\title{
Gastric perforation: unusual presentation of gastric lymphoma in pediatric population
}

\begin{abstract}
Gastric perforation is a potential fatal condition rarely occurs in children. We report a rare case of gastric perforation in a 3year old boy who was found to have gastric $\mathrm{T}$ cell lymphoma. Gastric lymphoma should be considered in the differential diagnosis of gastric perforation in children.
\end{abstract}

Keywords: gastric perforation, gastrointestinal non- hodgkin's lymphoma, gastric t-cell lymphoma

\author{
Volume 6 Issue 3 - 2017 \\ Smart Zeidan, ${ }^{2}$ Ramzi Hamzeh,' Elie \\ Bechara, ${ }^{3}$ Dany Al Hamod,' Fatima \\ Ghandour, ${ }^{4}$ Yolla Nassif' \\ 'Department of Pediatrics, Division of Neonatalogy, Saint \\ George Hospital University Medical Center, University of \\ Balamand, Lebanon \\ ${ }^{2}$ Department of Pediatric Surgery, Saint George Hospital \\ University Medical Center, University of Balamand, Lebanon \\ ${ }^{3}$ Department of Pediatrics, Division of hematology, Saint George \\ Hospital University Medical Center, University of Balamand, \\ Lebanon \\ ${ }^{4}$ Department of Pathology, Saint George University Hospital, \\ University of Balamand, Lebanon
} Surgery, Saint George University Hospital, Achrafieh, Beirut, Lebanon,Tel96171575625, Email smartzeidan@gmail.com

Received: February 02, 2017 | Published: February 21, 2017

\section{Introduction}

Gastric perforation is a rare entity in pediatric population. This case highlights the fact that gastric T-cell lymphoma should be considered in front of gastric perforation in children. A delayed diagnosis could be lethal.

\section{Case presentation}

A 3years old boy presented at the hospital with abdominal pain and severe abdominal distension after 5days history of fever treated with Nonsteroidal Anti-inflammatory drugs (NSAIDs). Abdominal $\mathrm{x}$-ray was done and raised the suspicion of pneumoperitoneum. Abdomen/ pelvis CT showed huge intraperitoneal ascites with pneumoperitoneum, normal liver and spleen with suspected perforation of the stomach (Figure 1: A: Pneumoperitoneum and Ascites. B: Suspected Gastric perforation). Patient underwent urgent laparotomy; gastric perforation was found and repaired. Gastric biopsies were done. Patient kept having fever post-operatively with distended and tender abdomen, abdomen/pelvis CT was repeated to rule out any abscess collection, and showed moderate amount of fluid in the abdomen, mainly anterior to the left colon. Collections showed compartmentalization, a CT- guided drainage done and 100cc of fluid were obtained and culture grew after 48hours in Leuconostoc and streptococcus mitis so Ceftazidime and Metronidazole were switched to Imipenem/Cilestatin. On Day 5 post-op, patient started to have severe abdominal pain with tachypnea and desaturation; abdomen/pelvis CT showed large amount of fluid in the peritoneal cavity, associated with thickening of the parietal peritoneum and re-perforation was suspected. Patient underwent urgent laparotomy where clear fluid was obtained, drain was placed, and biopsies from the liver, omentum and spleen were performed. Immunohistological examination of the gastric biopsies revealed an abnormal $\mathrm{T}$ cell lymph proliferation in favor of non-Hodgkin's T-cell lymphoma (Figure 2: Histopathology of the Gastric Biopsies. A: Low power view from ulcer base showing a diffuse infiltrate involving the full thickness of the gastric wall ( $\mathrm{H} \& \mathrm{E} \times \mathrm{40})$. B: Diffuse monotonous infiltrate involving the vessel wall (H\&E x 100). C: Medium sized convoluted nuclei with clear cytoplasm and scattered eosinophils (H\&E x 400). D: Diffuse membranous positivity of tumor cells with anti-CD3 (IHC $x$ 400). E: Staining with anti-CD20 shows negative tumor cells with positive residual germinal center. Few glandular Lumina with effaced epithelial lining are seen in the middle (IHC x 400).

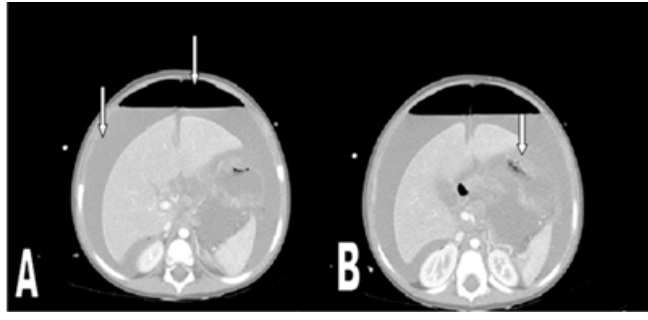

Figure I A: Pneumoperitoneum and Ascites. B: Suspected Gastric perforation.

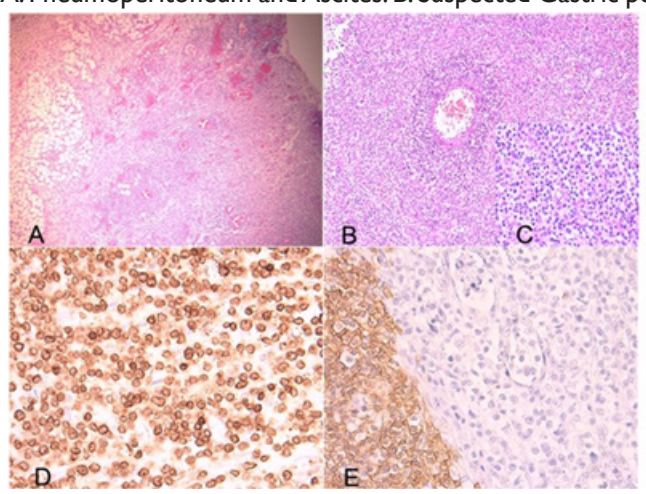

Figure 2 Histopathology of the Gastric Biopsies. A: Low power view from ulcer base showing a diffuse infiltrate involving the full thickness of the gastric wall (H\&E $\times$ 40). B: Diffuse monotonous infiltrate involving the vessel wall $(H \& E \times 100)$. C: Medium sized convoluted nuclei with clear cytoplasm and scattered eosinophils (H\&E x 400). D: Diffuse membranous positivity of tumor cells with anti-CD3 (IHC x 400). E: Staining with anti-CD20 shows negative tumor cells with positive residual germinal center. Few glandular Lumina with effaced epithelial lining are seen in the middle (IHC $\times 400)$. 
Patient received one cycle of chemotherapy (COP: Cyclophosphamide, vincristine prednisone) however patient was clinically and hemodynamically unstable and he was declared dead at day 12 of admission.

\section{Discussion}

Primary gastrointestinal (GI) tumors are rare entity in infancy and childhood and accounts for less than $5 \%$ of tumors in pediatric age group. ${ }^{1}$ Gastrointestinal lymphomas represent $1.0-1.2 \%$ of all pediatric malignancies, and compose $74-82 \%$ of GI-related malignancy. ${ }^{2}$ Primary non-Hodgkin's lymphoma of the GI tract is the most common extra nodal lymphoma in pediatric age group; however, most of them are of B-cell origin. T-cell lymphomas of the gastrointestinal tract are rare and most of the reported cases originated in the small intestine.$^{1,3}$ The majority of gastrointestinal tumors are non-Hodgkin's lymphoma, however studies on gastric lymphomas in childhood are limited to isolated case reports and most of these cases are Burkitt lymphoma and are associated with Helicobacter pylori infection. ${ }^{4}$ Gastric perforation is a rare entity in childhood. Peptic ulcer perforation, chronic steroid administration, NSAIDs, severe underlying illness, trauma, iatrogenic perforations are all reported as a differential diagnosis of gastric perforation. ${ }^{5}$ Perforation is a serious life-threatening complication of gastrointestinal lymphoma, for which high index of suspicion and early diagnosis is essential to avoid death.

The presentation of gastric lymphoma is often unspecific and more suggestive of gastritis or an ulcerous condition rather than a neoplasm; this is why its diagnosis is often delayed. Gastro-intestinal hemorrhage (hematemesis or melena) occurs at the outset in $20-30 \%$ of patients, while gastric occlusion and perforation are quite uncommon. ${ }^{6}$

To our knowledge, this is the first reported gastric perforation due to T-cell gastric lymphoma in pediatric population. A broad literature review of English-language relevant articles published in the last twenty years about pediatric gastric lymphoma revealed no reported Gastric T cell lymphoma and no reported gastric perforation due to lymphoma in pediatric population (Table 1).

Table I Literature review: Pediatric Gastrointestinal Tumors

\begin{tabular}{|c|c|c|c|c|}
\hline & $\begin{array}{l}\text { Gastrointestinal } \\
\text { tumors Number } \\
\text { of cases }\end{array}$ & $\begin{array}{l}\text { Gastric } \\
\text { tumors } \\
(\%)\end{array}$ & Histopathology of Gastric Tumors & $\begin{array}{l}\text { Presentation: Gastric } \\
\text { perforation (\%) }\end{array}$ \\
\hline Curtis JL, et al., ${ }^{4}$ & 21 & $21(100 \%)$ & $\begin{array}{l}\text { Gastric lymphoma 4(19\%): Burkitts } 3 \\
\text { MALToma I }\end{array}$ & 0 \\
\hline Zhuge Y, et al., ${ }^{8}$ & 105 & $64(61 \%)$ & $\begin{array}{l}\text { Carcinoma } 43(41 \%) \\
\text { Sarcoma } 46(43.8 \%) \\
\text { Neuroendocrine tumors II (I0.5\%) } \\
\text { Others } 5(4.7 \%)\end{array}$ & Not assigned \\
\hline Kassira N, et al., ${ }^{9}$ & 265 & $25(9.4 \%)$ & $\begin{array}{l}\text { Burkitt (53\%) } \\
\text { Other Non-Hodgkin's Lymphoma (43\%) } \\
\text { Mature T cell Lymphoma I* }\end{array}$ & 0 \\
\hline Morsi A, et al.., ${ }^{10}$ & 54 & $4(9.2 \%)$ & $\begin{array}{l}\text { Burkitts lymphoma } 55.8 \% \\
\text { Others(small cell non cleaved lymphoma, large } \\
\text { B cell lymphoma, and mixed type) }\end{array}$ & 0 \\
\hline $\begin{array}{l}\text { Ladd AP, et al.,"' } \\
\text { Bethel C, et al.," }\end{array}$ & $\begin{array}{l}58 \\
55\end{array}$ & $\begin{array}{l}I(I .7 \%) \\
3(5.4 \%)\end{array}$ & $\begin{array}{l}\text { Gastric leiomyosarcoma } \\
\text { Gastric sarcoma } 266.6 \% \\
\text { Non-Hodgkin's Burkitts lymphoma I } 33.3 \%\end{array}$ & $\begin{array}{l}0 \\
0\end{array}$ \\
\hline Zheng N, et al. , ${ }^{13}$ & 15 & $15(100 \%)$ & $\begin{array}{l}\text { Immature teratoma I } \\
\text { Vascular tumor I } \\
\text { Gastric adenomas } 2 \\
\text { Adenocarcinoma I } \\
\text { Inflammatory myofibroblastic tumor } 5 \\
\text { Epitheliomesenchymal biphasic tumor I } \\
\text { Mixed germ cell tumor I } \\
\text { Leiomyosarcoma } 2 \\
\text { Stromal tumors (epithelioid cell type) I }\end{array}$ & 0 \\
\hline Khurshed A, et al., ${ }^{14}$ & 60 & $3(5 \%)$ & $\begin{array}{l}\text { Signet Ring Cell Carcinoma } 2 \text { (66.7) } \\
\text { Adenocarcinoma, NOS I (33.3) }\end{array}$ & 0 \\
\hline
\end{tabular}

*One case of mature T cell lymphoma that was not assigned if in the stomach or other site of the Gl tract.

To date there is no ideal treatment approach in gastrointestinal lymphoma. A conservative approach consists of limited resection of obstructed or perforated segment, and biopsies to confirm the diagnosis ${ }^{2}$. However recent studies suggest that organ-preservation strategy using chemotherapy alone can be successfully employed in a significant number of patients with primary GI non-Hodgkin's lymphoma. ${ }^{7}$

\section{Conclusion}

Although gastric perforation is a rare entity in childhood, surgeon should consider gastric lymphoma in the differential diagnosis of gastric perforation and should take multiple biopsies in any suspicious case. 


\section{Acknowledgments}

None.

\section{Conflicts of interest}

Author declares there are no conflicts of interest.

\section{Funding}

None.

\section{References}

1. Bandyopadhyay R, Sinha SK, Chatterjee U, et al. Primary Pediatric gastrointestinal lymphoma. Indian $J$ Med Paediatr Oncol. 2011;32(2):92-95.

2. Ladd AP, Grosfeld JL. Gastrointestinal Tumors in Children. The Surgery of Childhood Tumors. Springer Berlin Heidelberg. 2016;257-267.

3. Horie R, Yatomi Y, Wakabayashi T, et al. Primary gastric T-cell lymphomas: report of two cases and a review of the literature. Jpn J Clin Oncol. 1999;29(3):171-178.

4. Curtis JL, Burns RC, Wang L, et al. Primary gastric tumors of infancy and childhood : 54-year experience at a single institution. J Pediatr Surg . 2008;43(8):1487-1493.

5. Morrison S, Ngo P, Chiu B. Perforated Peptic Ulcer in the Pediatric Population: A Case Report and Literature Review. Journal of Pediatric Surgery Case Reports. 2013;1(12):416-419.
6. Ferrucci PF, Zucca E. Primary gastric lymphoma pathogenesis and treatment: what has changed over the past 10 years? Br J Haematol. 2006;136(4):521-538.

7. Raina V, Sharma A, Vora A, et al. Primary gastrointestinal non-Hodgkin lymphoma chemotherapy alone an effective treatment modality: Experience from a single center in India. Indian J Cancer . 2006;43(1): $30-35$.

8. Zhuge Y, Cheung MC, Yang R, et al. Pediatric Intestinal Foregut and Small Bowel Solid Tumors: A Review of 105 Cases. J Surg Res. 2009;156(1):95-102.

9. Kassira N, Pedroso FE, Cheung MC, et al. Primary gastrointestinal tract lymphoma in the pediatric patient: review of 265 patients from the SEER registry. J Pediatr Surg. 2011;46(10):1956-1964.

10. Morsi A, Abd El-Ghani Ael-G, El-Shafiey M, et al. Clinico-Pathological Features and Outcome of Management of Pediatric Gastrointestinal Lymphoma. J Egypt Natl Canc Inst. 2005;17(4): 251-259.

11. Ladd AP, Grosfeld JL. Gastrointestinal tumors in children and adolescents. Semin Pediatr Surg. 2006;15(1):37-47.

12. Bethel C, Bhattacharyya N, Hutchinson C, et al. Alimentary tract malignancies in children. J Pediatr Surg . 1997;32(7):1004-1008.

13. Zheng N, Xiao XM, Dong KR, et al. Primary gastric tumors in infants and children: 15 cases of 20-year report. Journal of Cancer Research and Clinical Oncology J Cancer Res Clin Oncol . 2016;142(5):1061-1067.

14. Khurshed A, Ahmed R, Bhurgri Y. Primary Gastrointestinal Malignancies in Childhood and Adolescence - an Asian Perspective. Asian Pac J Cancer Prev. 2007;8(4):8613-8617. 